\title{
OJS OPEN

\section{PRÁTICA E PRODUÇÃO DE MATERIAIS DIDÁTICOS PARA O ENSINO DE GEOGRAFIA: UMA PROPOSTA METODOLÓGICA PARA O ENSINO ESCOLAR A PARTIR DA EXPERIÊNCIA NO ENSINO ACADÊMICO}

\author{
Daiane Alencar Silva ${ }^{1}$, Carlos Eduardo Dourado Ramires ${ }^{2}$, Gabriela Ferreira de Souza ${ }^{3}$, \\ Vitor José Ribeiro Amaral Neto ${ }^{4}$, Valdemir Pomerening de Mello Júnior ${ }^{5}$ \\ ${ }^{1}$ Doutora em Geografia. Docente contratada da Universidade Estadual de Mato Grosso do Sul. E-mail: \\ daianeufgd@hotmail.com - ORCID iD: http://orcid.org/0000-0001-5506-5387 \\ ${ }^{2}$ Acadêmico do curso de Geografia Licenciatura da UEMS. E-mail: kduuems@gmail.com - ORCID iD: \\ http://orcid.org/0000-0003-2186-2833 \\ 3 Acadêmica do curso de Geografia Licenciatura da UEMS. E-mail: gabrielazfs@gmail.com - \\ http://orcid.org/0000-0003-2186-28XX \\ ${ }^{4}$ Acadêmica do curso de Geografia Licenciatura da UEMS. E-mail: vitorjose01@hotmail.com - ORCID \\ iD: http://orcid.org/0000-0003-4684-76XX \\ 5 Acadêmica do curso de Geografia Licenciatura da UEMS, E-mail: valdemirdemello@gmail.com - \\ ORCID iD: http://orcid.org/0000-0001-8747-8338
}

Artigo recebido em 27/08/2019 e aceito em 05/02/2020

\begin{abstract}
RESUMO
A Geografia escolar brasileira pauta-se ainda num modelo de ensino tradicional, contemplando práticas de ensino onde o estudante é levado a decorar o conteúdo, não contribuindo satisfatoriamente para o desenvolvimento de um pensamento crítico a respeito de si, da construção do ser, individual e coletivo e da sociedade em que está inserido. No sentido de romper essa barreira no ensino é que emergem diferentes propostas didáticas e metodológicas para a promoção de aulas mais comprometidas em despertar nos estudantes o pensamento crítico acerca de seu cotidiano. Dentre elas, os materiais didáticos são importantes instrumentos que auxiliam o professor em sala de aula, dando dinamicidade ao conteúdo abordado, contribuindo de maneira significativa para que o processo de ensino-aprendizagem ocorra de maneira a romper com o modelo tradicional ainda utilizado. Assim, este artigo é uma proposta de contribuir para a superação do modelo tradicional, tendo como objetivo apresentar metodologias para a criação de materiais didáticos para o ensino de Geografia, a partir da experiência acadêmica. Tendo como procedimentos metodológicos duas etapas, a primeira uma revisão teórica sobre o tema e na segunda apresenta-se a elaboração dos materiais desenvolvidos pelos acadêmicos do curso de graduação em Geografia Licenciatura contextualizando-os com o conteúdo abordado.
\end{abstract}

Palavras-chave: Materiais didáticos; ensino; Geografia. 


\title{
PRACTICE AND PRODUCTION OF TEACHING MATERIALS FOR TEACHING GEOGRAPHY: A METHODOLOGICAL PROPOSAL FOR SCHOOL TEACHING FROM THE EXPERIENCE IN ACADEMIC TEACHING
}

\begin{abstract}
Brazilian school geography is still based on a traditional teaching model, contemplating teaching practices where the student has to decorate the content, not contributing satisfactorily to the development of critical thinking to yourself, the construction of the individual and collective being and the Society inserted. In order to break this barrier in teaching, diferente didactic and methodological proposals for the promotion of more committed classes in arouse in students the critical thinking about their daily lives. Among them, the didactic materials are important tools that help the teacher in the classroom, assisting the dynamics to the content addressed, contributing significantly for learning process to occur in a way that breaks with the model traditional yet used. Thus, this article is a proposal to contribute to the overcoming of the traditional model, aiming to present methodologies for the creation of didactic materials for the teaching of geography, from the experience academic. As methodological procedures, we had two stages, the first one theoretical review on the topic and the second presents the elaboration of the materials developed by undergraduate academics in Geography Degree contextualizing them with the content covered.
\end{abstract}

Keywords: Didactic materials; teaching; Geography.

\section{INTRODUÇÃO}

A formação acadêmica para futuros docentes da rede básica de ensino requer metodologias e práticas que proporcionem um aprendizado coerente com a realidade vivenciada nas escolas, principalmente, as públicas. Isso devido os desafios e obstáculos impostos pelas condições insatisfatórias da rede de ensino brasileira, no que diz respeito a infraestrutura e disponibilidade de recursos para o aprimoramento de atividades que envolvam materiais didáticos e possibilitem a superação do ensino da geografia tradicional, pautada, principalmente, no livro didático, ou seja a "bíblia" em sala de aula.

Cabe ressaltar, que não é nossa intenção questionar a aplicabilidade e importância do livro didático, mas sim a maneira de utilização do mesmo. Ainda vemos professores usando apenas o livro como aporte teórico e metodológico em suas aulas, não se aventurando em oferecer algo a mais na formação escolar, mesmo diante de um cenário que exige a interação de novas práticas e métodos de ensino, assim como o uso de tecnologias.

É amplamente discutido nas pesquisas educacionais em geografia, o desinteresse dos estudantes pelas disciplinas, principalmente, das ciências humanas, nas escolas, o que por vezes dá interpretação para mudanças no currículo escolar como forma de superar tal desinteresse. Sendo que nesse quadro, a mudança essencial não está na formulação de um novo currículo, mas essencialmente, na forma de trabalho, na aplicação do conteúdo em 
sala de aula e nas práticas de ensino. É preciso renovar o método de ensino-aprendizagem da Geografia e introduzir as mudanças que estão ocorrendo na sociedade, como por exemplo, o avanço tecnológico. Mas para isso, há um longo percurso a ser trilhado, a começar pela formação docente dos futuros professores e, um pouco antes, no aperfeiçoamento dos próprios docentes do ensino superior, afinal de contas, como ensinar a mudar algo se não se sabe como mudar?

O desafio é oferecer aos discentes uma formação de qualidade, coerência e proximidade com a realidade que enfrentarão nas salas de aulas do país. Com isso, cabe aqui expor como se deu a experiência de ministrar a disciplina de Prática e Produção de Materiais Didáticos para o ensino de Geografia, no curso de graduação em Geografia Licenciatura, da Universidade Estadual de Mato Grosso do Sul, levando em consideração a proposta do curso, através da ementa curricular e da metodologia de ensinoaprendizagem utilizada para alcançar os objetivos propostos no plano de ensino.

Sendo assim, o objetivo dessa pesquisa é apresentar metodologias para a criação de materiais didáticos para o ensino de geografia, a partir da experiência no ensino acadêmico. Para isso, utilizam-se como procedimentos metodológicos, nesse artigo, duas etapas, sendo a primeira parte pautada em revisão teórica sobre o tema em questão: metodologias de ensino e produção de materiais didáticos e, em seguida os recursos utilizados para ministrar a disciplina como o plano de ensino, composto pela ementa e conteúdo programático. Na segunda etapa apresenta-se a elaboração dos materiais desenvolvidos pelos acadêmicos do curso de graduação em Geografia Licenciatura contextualizando-os com o conteúdo abordado.

Com esse trabalho, busca-se propor uma metodologia de ensino que aproxime o acadêmico da realidade das escolas públicas brasileiras, que em sua maioria, apresentam deficiências quanto a disponibilidade de recursos didáticos para o ensino de Geografia, além de promover o ensino de uma ciência em movimento, em constante mudança e que por isso não deve se pautar somente em métodos tradicionais de ensino. É preciso construir novas metodologias de ensino com aquilo que nos é disposto. Esse é outro desafio. 


\section{REVISÃO TEÓRICA}

A geografia escolar no Brasil apresenta bases calcadas num ensino tradicional, hegemônico, baseado em um procedimento de “decoreba", fragmentados em aspectos físicos e humanos, como aponta o autor:

Isto é perceptível tanto no estudo do Brasil quanto dos continentes que, ainda, mantém a ideia de analisar, sequencialmente, os aspectos físicos, populacionais e econômicos, apontando as particularidades de cada localidade e sem, muitas vezes, estabelecer relações entre eles. (MOREIRA JUNIOR, 2016, p.28).

Essa base positivista, de certa forma, contraria um dos aspectos fundamentais da Geografia que é compreender os diferentes fenômenos com um olhar crítico e interrelacionado, dando condições para que os estudantes interprete a realidade onde vivem de maneira integrada, e não apenas decorando informações. Nesse sentido, Copatti (2017, p.54) afirma que há "[...] necessidade de se pensar uma Geografia que auxilie a compreensão do mundo e de suas transformações. A Geografia Escolar tem um papel importante por atuar na conscientização dos educandos [...]”.

Propor metodologias que auxiliem os estudantes a construir seu próprio conhecimento, mediado pelo professor, é necessário primeiro compreender que o papel do professor é estimular o estudante a questionar aquilo que lhe é apresentado como verdade. Esse processo denomina-se de lógica dialética, onde "cabe ao professor planejar suas aulas, utilizando-se de diferentes linguagens para que sua aula não seja tradicional e buscando uma lógica que não seja a formal" (FIORI, 2019, p.7).

Fugir do padrão da lógica formal, do ensino tradicional é um grande passo. Permitir ao estudante compreender o que existe além das aparências dos fenômenos, refletir sobre seu contexto social, cultural, econômico, ambiental, etc., desperta o interesse pela ciência geográfica, contribuindo para um ensino-aprendizado mais dinâmico e próximo da sua realidade.

Entretanto, para que isso ocorra é necessário que o professor estimule nos estudantes o desejo de contribuir com o conhecimento pré-existente, o respeito ao que o estudante carrega como experiência de vivência pode ser um grande aliado nesse processo, uma vez que este sinta-se atuante na construção e reflexão das coisas que o cercam. Partir da realidade do estudante é fundamental para compreendê-lo. 
Para isso, deve-se levar em conta o conhecimento que o estudante já possui, através do dia a dia que se constrói a percepção de mundo e suas relações, conforme assinala Callai (2005, p.233): "E se, quando se lê a palavra, lendo o mundo, está-se lendo o espaço, é possível produzir o próprio pensamento, fazendo a representação do espaço em que se vive”. Dessa maneira, a própria sala de aula é o espaço de referência do sujeito, de onde projeta-se expectativas, como aponta Carlos $(2018$, p.8) "[...] a sala de aula pode ser o locus privilegiado do exercício da crítica (inerente ao ato de conhecer), da possibilidade de manifestação do diferente, um espaço da afirmação do conhecimento, de alimentação da paixão pela descoberta, do estímulo e da reflexão".

Nesse contexto, pontua-se outro desafio encontrado dentro da geografia escolar que é o livro didático, muitas vezes utilizado como único aporte para o planejamento e execução das aulas e atividades. Além disso, discute-se o seu conteúdo, pois na maioria das vezes acabam reproduzindo a Geografia tradicional, mantendo um estudo em "gavetas", onde os conteúdos não se relacionam entre si.

\begin{abstract}
Atualmente, embora muito já se tenha progredido a fim de tornar os livros didáticos mais coerentes à aprendizagem escolar, é necessário que se avance na qualidade e atualização de conteúdos, conceitos, informações e no atendimento à formação cidadã, visto que, mesmo com progressos principalmente na última década, há ainda certa resistência na adequação de determinados temas nos materiais didáticos (COPATTI, 2017, p.78).
\end{abstract}

Além disso, deve-se citar a perspectiva econômica que o livro didático possui: valor mercadológico. Nesta perspectiva, nota-se que a produção de livros didáticos também perpassa pela geração de lucros, o que pode ocasionar, em termos de conteúdo, a perda do caráter teórico de propiciar ao estudante o desenvolvimento de um pensamento crítico, ou seja, "Nisso se evidencia o caráter mercadológico do livro didático, considerado, além de um objeto político e cultural, uma mercadoria" (COPATTI, 2017, p.78).

Deve-se mencionar a importância que o livro didático possui enquanto um aporte teórico para os conteúdos a serem ministrados em sala de aula, desde que seja utilizado de maneira coerente pelo professor e não como única referência de pesquisa.

Ao planejar o uso do livro didático nas aulas de geografia é necessário ter em mente que este recurso serve de complemento ao trabalho e como fonte de pesquisa ao estudante. Para cada ocasião, para cada turma e em cada contexto educacional, o livro didático pode ou não se configurar como adequado/necessário (COPATTI, 2017, p.90-91). 
Diante do exposto, cabe ao professor encontrar meios de romper com a prática de ensino pautada no positivismo, buscando outras formas possíveis de desenvolver a Geografia em sala de aula de maneira mais atraente aos estudantes, auxiliando-os a refletir sobre o mundo e a sociedade. Dessa necessidade é que surgem os materiais didáticos, como recursos que complementam o ensino.

Os materiais didáticos são instrumentos que auxiliam o professor na abordagem de diferentes conteúdos, dando mais dinamicidade as aulas e contribuindo de forma significativa para a construção do aprendizado do estudante. Jogos, atividades lúdicas, maquetes, teatro, músicas, oficinas, fantoches, exposições, aulas de campo, etc., são exemplos que podem ser utilizados pelo professor para ministrar aulas de maneira mais atrativa, abarcando o conteúdo previsto e transmitindo ao estudante uma condição de refletir sobre aquilo que lhe é exposto através de outros olhares, outras linguagens.

Vale ressaltar, que o professor precisa estar atento ao uso desses instrumentos, para que não fiquem desconexos do conteúdo ou mesmo da condição de aprendizagem dos estudantes, as turmas e suas faixas etárias precisam ser cautelosamente atendidas em suas diferenciações/especificidades.

É papel do professor, como mediador no processo de ensino-aprendizagem, saber escolher o recurso didático e utilizá-lo de forma adequada, problematizar o conteúdo e observar os objetivos que pretende alcançar, o público-alvo e o conteúdo ministrado (COSTA; DAMASCENO; MUNIZ, 2018, p.95).

Nessa perspectiva, compreende-se a relevância do uso de materiais didáticos em sala de aula, promovendo um processo de ensino-aprendizagem diferenciado do método tradicional, onde o estudante senta-se no seu lugar, abre o livro didático e recebe o conteúdo do professor, não participando ativamente do processo. Porém, é preciso destacar que as condições impostas aos professores na rede de ensino brasileira, em alguns casos, são insuficientes, pois ainda que existam cursos de formação, disponibilização de várias tecnologias e outras linguagens para uso dos professores, percebe-se de modo geral que as maiores dificuldades encontradas estão relacionadas as condições de trabalho, que não fornece ao professor de Geografia meios para o desenvolvimento de tais práticas, devido a diversos fatores, entre eles falta de estrutura em unidades escolares, elevada quantidade de turmas para preenchimento de carga horária do professor, número elevado de estudantes em sala de aula, horários de aulas separados, etc. 
Notadamente não se devem generalizar tais condições, tendo em vista que no país há casos díspares, com condições semelhantes de trabalho. Nesse caso, é importante levar em consideração a formação docente, o contexto em que o professor está inserido, entre outros aspectos, que cabe numa discussão em momento oportuno.

Nesse sentido, cabe aqui apontar a experiência vivenciada com a produção e uso de materiais didáticos para o ensino de Geografia como um instrumento passível de ser utilizados pelos professores em sala de aula. Refletindo sobre as dificuldades encontradas, especialmente em relação a recursos financeiros, as propostas que serão apresentadas foram realizadas com custo baixo de produção, justamente buscando ser exemplo de atividades que não necessitam de aportes financeiros para serem executadas.

Os materiais didáticos foram elaborados e produzidos a partir da disciplina de Prática e Produção de Materiais Didáticos para o ensino de Geografia. Essa disciplina é componente do Projeto Pedagógico do curso de Geografia Licenciatura ${ }^{1}$ e possui carga horária de 68h/aulas, sendo $08 \mathrm{~h} / \mathrm{a}$ de parte teórica e 60h/a de prática como componente curricular, ou seja, produção de material didático-pedagógico.

$\mathrm{Na}$ composição das aulas teóricas a disciplina oferece leituras orientadas, que permitem o aprofundamento e debate sobre temas relacionados a práticas de ensino, além de atividades direcionadas ao estudo teórico. Compondo as aulas práticas (com maior carga horária) a disciplina direciona os acadêmicos a produzirem materiais didáticos que proporcionem o aprendizado da elaboração/confecção/construção dos mesmos além de relacioná-los a conteúdos presentes no livro didático de Geografia, utilizados na rede básica de ensino do município.

\section{ELABORAÇÃO DOS MATERIAIS DIDÁTICOS}

Para a realização da elaboração dos materiais didáticos, utilizou-se a subdivisão em três ciclos, sendo o primeiro voltado para o ensino fundamental, o segundo para o ensino médio e por fim, o terceiro ciclo destinado aos estudantes com deficiência, ficando a critério de cada grupo de trabalho escolher o tipo de necessidade que abordaria.

A metodologia de trabalho aplicada para a elaboração dos materiais didáticos com os acadêmicos foi dividida em etapas. A primeira etapa deu-se pela definição/escolha dos

\footnotetext{
${ }^{1}$ Curso de Geografia Licenciatura da Universidade Estadual de Mato Grosso do Sul - Unidade de Campo Grande/ MS.
} 
conteúdos a serem abordados. Os acadêmicos foram instruídos a realizar uma análise do livro didático da rede básica de ensino, disponível no Laboratório de Ensino da Universidade. Para isso, reuniram-se em grupos de trabalho e, após realizar a escolha do conteúdo (tema da aula) e a série, precisaram elaborar o Plano de Aula, descrevendo o objetivo, conteúdo, procedimentos metodológicos e recursos didáticos adotados na atividade proposta.

Na segunda etapa os acadêmicos organizaram o plano inicial do produto, ou seja, o planejamento "do que" e do "como" fazer, servindo de base para refletir sobre as condições disponíveis para a execução da proposta.

A terceira etapa pautava-se na elaboração, propriamente dita, dos materiais, conforme imagem a seguir. Os grupos de trabalhos tinham a disposição materiais diversos como cartolinas, papel crepom, placas de isopor de espessuras variadas, tintas e pincéis, cola, etc. Materiais acessíveis de baixo custo.

Figura 1. Etapa de elaboração dos materiais didáticos no laboratório.

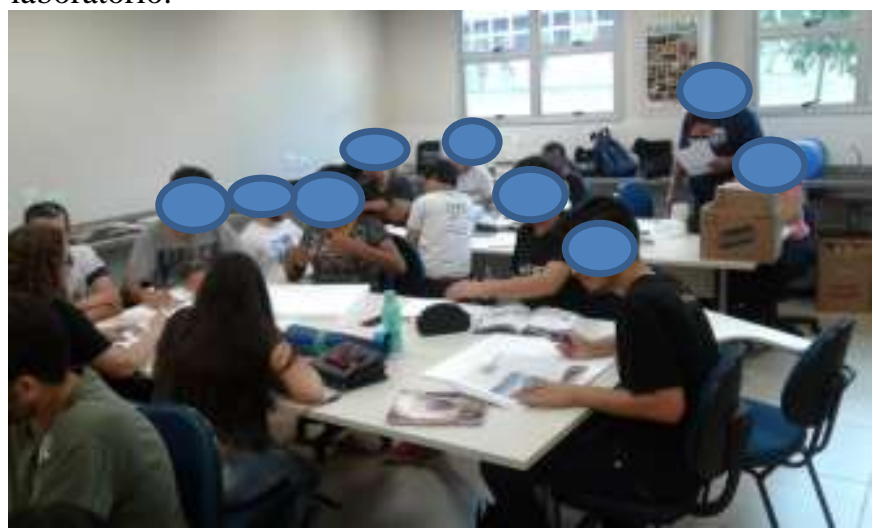

Fonte: Autores, 2018.

A quarta etapa foi disponibilizada para os acadêmicos testassem os materiais produzidos, em casos de jogos, por exemplo, para que não houvesse incoerências no processo de aplicabilidade.

A quinta e última etapa destinou-se a apresentação do Kit Didático em sala de aula, em formato de Simulação de aula. O Kit era composto pelo material didático e Plano de Aula, impresso, entregue ao docente no momento da apresentação.

Ressalta-se, que todas as etapas de produção, dos três ciclos, foram realizadas no âmbito acadêmico (laboratórios e sala de aula) sob a supervisão e orientação da docente responsável pela disciplina. 
Nesse trabalho, apresenta-se o resultado dessa atividade, pela perspectiva de um grupo de trabalho, que optou para o ciclo no ensino fundamental o tema correntes marítimas e fluxos migratórios, gerando o "Mapa Interativo do Continente Americano". No ensino médio, a opção foi o tema migrações forçadas e o tráfico de mulheres, gerando o material didático denominado "Dan e Ianne, os fantoches". E na terceira produção, voltada para atender estudantes com deficiências, em específico o autismo, foi elaborado o "Varal geográfico: vida pantaneira".

Para o ensino fundamental, o grupo de trabalho elaborou o Mapa Interativo do Continente Americano, trazendo à discussão o tema trabalhado no livro didático sobre correntes marítimas, destacando-as com setas (produzidas em material emborrachado tipo EVA) que eram fixadas com auxílio de alfinetes. Para permitir o envolvimento dos colegas de sala, o grupo elaborou um Quiz com perguntas e respostas rápidas e lúdicas, aqueles que acertassem podiam direcionar as setas no Mapa Interativo (confeccionado em placa de isopor). A seguir exemplos de perguntas:

- Qual corrente marítima que mais possui piratas? Resposta: Corrente do Caribe.

- Qual é a corrente marítima que mais possui golfinhos? Resposta: Corrente do Golfo.

O que se percebe com essa prática, além da diversão gerada pelas perguntas, é o envolvimento da grande maioria pela ludicidade que o jogo apresenta, principalmente porque oferece a interatividade na produção final do mesmo, através da fixação das setas, como demostra na imagem a seguir.

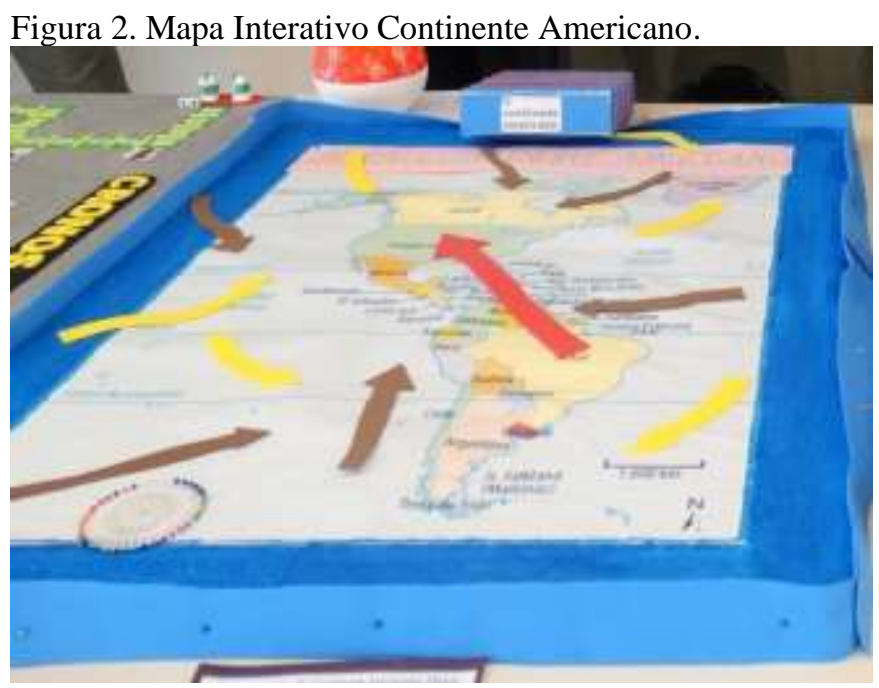

Fonte: Autores, 2018. 
Já no tema de fluxos migratórios, seguindo a mesma lógica do anterior, os acadêmicos também elaboraram um jogo em formato de Quiz no intuito de promover a participação de todos em sala de aula. Segue os exemplos:

- Qual a migração impedida por um muro? (sotaque espanhol na pronuncia da pergunta). Resposta: Estados Unidos e México.

- Do país tropical, verde e amarelo, para o país que mais doa cana? Resposta: Brasil e Canadá.

- A sopa que não é sopa, e que mesmo assim comemos? Resposta: Paraguai e Brasil.

Para o ensino médio, escolheu-se o tema migrações forçadas e o tráfico de mulheres, para produzir uma encenação com fantoches (confeccionados em tecido) gerando o material didático denominado "Dan e Ianne, os fantoches". Essa proposta utilizou-se da discussão do tema migrações forçadas, e mais especificamente dos refugiados e do tráfico internacional de mulheres. Para tanto foram usados poemas para amenizar possíveis impactos relacionados às histórias de vida abordadas na apresentação. Isso se deve ao fato da proposta ser direcionada aos estudantes adolescentes do ensino médio.

A história fora narrada por três fantoches (conforme imagem a seguir), onde um era caracterizado como um sírio, outro fantoche representava uma mulher, vítima do tráfico e, um terceiro seria um MC (mestre de cerimônia). Na apresentação, o personagem do sírio recitou seu poema, abarcando os sentimentos da dor e as experiências vividas em sua jornada de fuga. Já o fantoche da mulher traficada, também por meio de poema, relatava as tormentas e traumas vividos no período em que esteve sob exploração sexual.

Figura 3. Fantoches utilizados para encenação.

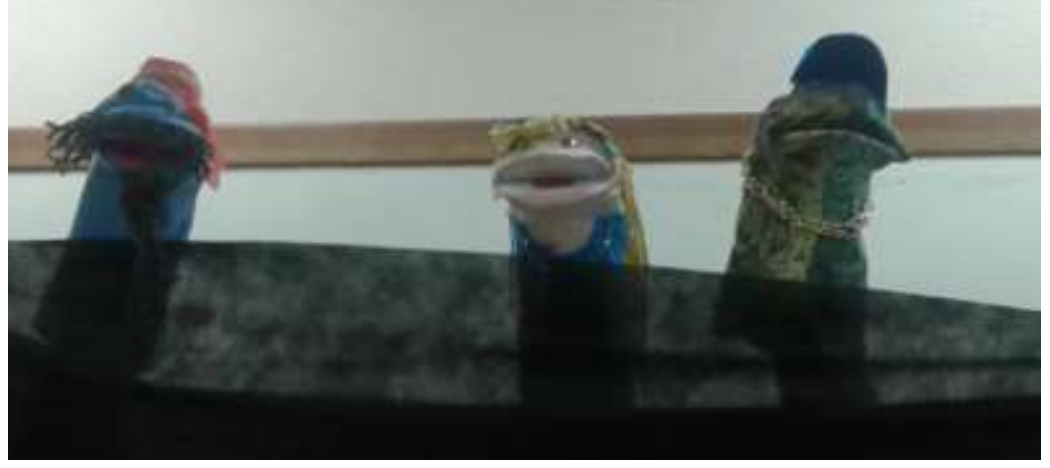

Fonte: Autores, 2018. 
Para elaboração dos poemas foram utilizados relatos reais, no caso do sírio ${ }^{2}$ foram abordados sete relatos de quem passou e sobreviveu aos horrores da guerra. Já no poema da mulher que sofreu tráfico sexual, foi utilizado relato de uma moça nascida na Indonésia e que foi traficada ainda jovem ${ }^{3}$.

E o terceiro fantoche MC cantava funk exemplificando as três histórias, este foi utilizado como artifício para buscar a atenção dos adolescentes, uma vez que o funk está na cultura e no cotidiano da grande maioria. Seguem os poemas das duas situações de migrações forçadas:

Tráfico de mulheres.

O ano é 1998, na Indonésia habito

Com minha filha em um lar afetivo.

Estudei finanças, para ter alguma segurança.

Com ensino superior, um bom emprego achei que tinha!

Mas a crise veio e levou tudo o que podia.

De início a crise econômica, posterior a guerra política

Sem paz e sossego em nenhum dia existia.

Em meio a está crise, perdi o trabalho e a segurança

Minha filha eu precisava criar, agora emprego não há.

Fui a busca de alguma oportunidade, quando um anuncio eu vi.

Mas logo de sua veracidade não compreendi.

A oferta era tentadora, trabalhar em grandes hotéis em diferentes países

Estados Unidos, Japão, Hong Kong e Singapura

Nesta etapa da vida eu já estava sem nenhuma armadura

Pronta para sonhar com uma vida melhor sem excitar.

Me lancei ao tal emprego, com muitos desejos

Mas logo de início parecia haver um precipício

De um investimento inicial eu precisava

Pagando para trabalhar, aonde isso iria me levar?

Depois de tanto martírio, de precisar pagar para trabalhar

E um pouco de inglês falar, consegui o serviço, aparentemente

As coisas viraram ao meu favor, mas ali começava a real dor.

Para os Estados Unidos fui designada, contratada agora estava,

Não parava de pensar em dinheiro ganhar, pois,

para casa então eu voltaria, para cuidar de minha filha.

Comigo estavam mais quatro mulheres a compartilhar talvez

Da mesma sina, qual o mal nos esperaria em cada esquina?

Logo no aeroporto de Nova York chegamos.

\footnotetext{
${ }^{2}$ Disponível em: https://observador.pt/2015/09/22/sete-historias-marcam-crise-refugiados/

${ }^{3}$ Disponível em:

https://www.bbc.com/portuguese/noticias/2016/04/160330_escrava_sexual_eua_relato_lgb
} 
Poema de refugiado Sírio:

Histórias de um fantoche: fuga da Guerra

Ouçam com atenção

Pois as histórias que eu vou contar

Podem algumas lágrimas derramar.

São cenas reais de dor e tristeza,

Que vem na minha cabeça com clareza.

Fatos que mostram como a guerra é terrível

Ver um irmão um amigo, morto ou ferido.

A Guerra é muito mais cruel do que se vê na televisão

Armas atirando sem nenhuma direção

Dando corda a solidão.

Pessoas rodeadas de caos e desespero,

Todas com um único desejo

De que novamente suas vidas possam prosperar

Com um futuro querem sonhar.

Minha história infelizmente é como a de muitos outros

Rodeada de problemas com muitas divergências

Buscando a todo instante, um lugar que não seja degradante

Pois a Guerra me forçou ao meu lar abandonar

Minha família e amigos deixar

Com tristeza em meu olhar.

Mas antes de mais nada

Irei contar algumas histórias um tanto quanto pesadas

De conhecidos meus que também deram algum adeus.

A primeira delas é sobre um pai

Que junto de sua família

fugia da Síria.

Com eles iria, até a Grécia.

Mas, ainda cedo na Turquia

Com um grande grito sofria.

Com um naufrágio durante a noite

Viu a alvorada ensanguentada

Na praia o corpo de seu filho,

morto por vaidade da guerra,

criada por monstros que andam pela terra,

e sem contar ainda que o resto de sua família perdeu

para onde voltaria, sem um lar e nenhuma alegria?

Outras dessas histórias, novamente de um pai

Que seu lar foi tomado pelo Estado Islâmico

Sem lugar para ir o que sobrava era vagar por ai.

Junto de seu filho em seus braços

Fez o que pode para o proteger

Dia a dia tentando sobreviver

Osama que era seu nome, chegou a Hungria

$\mathrm{O}$ que ali esperava além de sangria? 
Por um momento feliz, a volta por cima

Conseguiu dar, sem nenhum excitar.

Descobriram sua profissão, técnico de futebol ele era,

A perseverança o deixou que pudera, continuar

Sem momento nenhum parar.

Um time se compadeceu de sua história

E um emprego lhe deu,

Agora era treinador de um time juvenil ele era.

Um futuro melhor o espera

Agora pode comemorar sem pressa.

O que os pais não fazem para proteger um filho?

Mesmo que sejam andarilhos, os defendem com unhas e dentes.

Esta outra história com sua carga de tristeza

Novamente os olhos mareja.

Um homem vendendo canetas,

Ao que parece nada muito incomum

Não fosse o fato de que carrega sua filha no ombro

Em meios aos escombros de sua vida.

Ele reside no Líbano, e um futuro tenta encontrar

Para sua filha alimentar, canetas ele vende

Um fato nada surpreendente como a guerra devasta

Sem nenhum precedente.

$\mathrm{Na}$ aurora, uma família chora

Chegaram na Grécia, depois de um naufrágio

Em seus olhos viram sua vida quase sucumbir

Em um alento conseguiram emergir.

A tristeza para eles caminham lado a lado

De fato vivos após vários atentados

E tristes sem saber para qual lado ir

A vida infelizmente se torna um mártir.

Mas ainda o que prevalece é o sorriso

Em meio a angústia e dor

O carinho da família traz algum calor

De um amor afetuoso que juntos permanecem

Sempre junto das preces.

Difícil, tantas histórias eu contar,

Sem não me emocionar

Olhos a todos os instantes carregados

Vendo a dor de segregados

Vidas que por vaidade se desfazem

Guerras por poder

Que fazem a todos sofrer.

Incontáveis casos já conheci

Alguns com desfechos felizes outros nem tanto

O que fica é os prantos

A dor e solidão de perder a família

Caso triste, pesada sina.

O amor perdido dos teus

É com uma estaca no peito 
Sem nenhum respeito

A dor é agonizante o futuro parece distante.

A claro, minha real história não contei em detalhes?!

Um pai que perdeu tudo fugindo

A guerra vinha como um leão rugindo

Minha esposa vi ser morta por uma explosão

Adaga cravada em meu coração.

Meu filho, perdi em meio a aventura de lá sair

Com um tiro, vi a vida deles deixar de existir.

Agora cá estou, contanto estas histórias

Sem querer relembrar a dor.

Peço que ao terminarem de me escutar

Fiquem na reflexão

Será que é este mundo que queremos para

Nossos filhos, pai e mãe e nosso irmão?

E por último, o terceiro ciclo almejava a produção de materiais didáticos para estudantes com deficiências. $\mathrm{O}$ autismo foi a escolha do grupo, visando promover a discussão em sala sobre a educação inclusiva e o papel do professor frente a essa realidade. Sobre isso, nota-se na Constituição Brasileira de Inclusão ${ }^{4}$ que:

\begin{abstract}
A educação constitui direito da pessoa com deficiência, assegurados um sistema educacional inclusivo em todos os níveis e o aprendizado ao longo de toda a vida, de forma a alcançar o máximo desenvolvimento possível de seus talentos e habilidades físicas, sensoriais, intelectuais e sociais, segundo suas características, interesses e necessidades de aprendizagem (BRASIL, 2015).
\end{abstract}

Dessa maneira, é preciso promover espaços de reflexão sobre o autismo, assim como de inclusão das pessoas, principalmente no âmbito escolar. Então, o grupo se propôs a elaborar um material e atividade que permitisse essa inserção em sala de aula, levando em consideração a permanências de estudantes com autismo.

O produto chamado de "Varal Geográfico: Vida Pantaneira" (feito de barbante, prendedor de roupa, EVA, folha sulfite, cola e tinta) tem como objetivo trabalhar a questão de região e lugar no recorte espacial de Mato Grosso do Sul, estimulando os estudantes através da exposição de imagens e versos (poesias e letras de músicas) sobre o conteúdo em análise. A ideia de abordar o conteúdo de maneira visual se conecta com a facilidade de melhor compreensão do tema, do conteúdo e da associação entre teoria e prática.

Nas imagens a seguir pode-se analisar a maneira simples de confecção do produto.

\footnotetext{
${ }^{4}$ Disponível em: http://www.planalto.gov.br/ccivil_03/_Ato2015-2018/2015/Lei/L13146.htm acesso em $12 / 01 / 2019$.
} 
Figura 4. Exposição do Varal Geográfico: vida pantaneira.

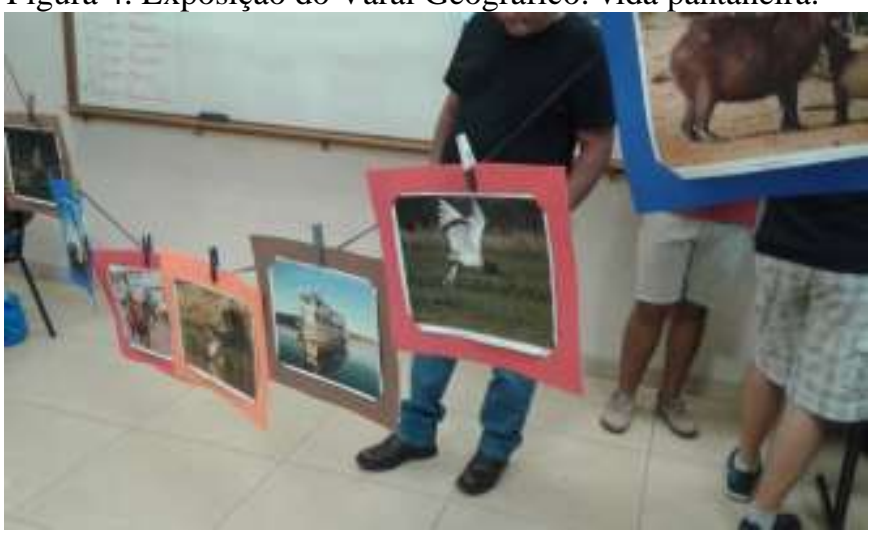

Fonte: Autores, 2018.

Figura 5. Exposição do Varal Geográfico: vida pantaneira.

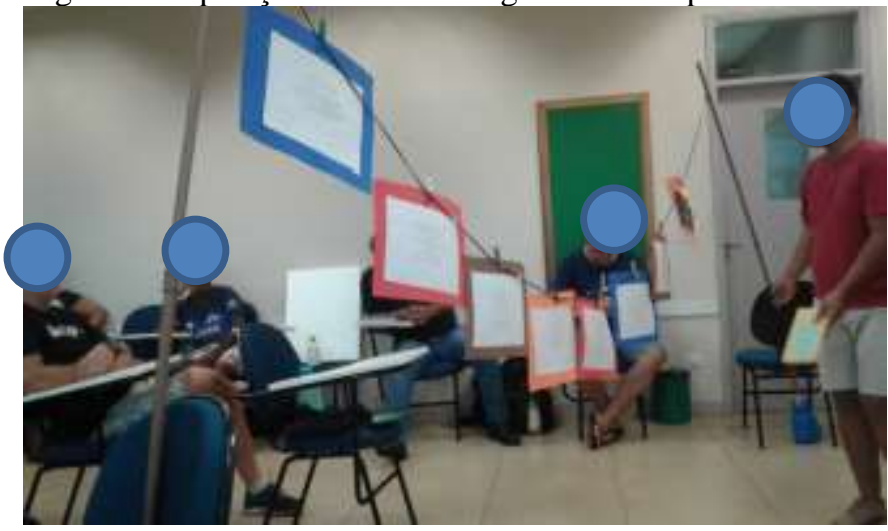

Fonte: Autores, 2018

A opção pela subdivisão em três ciclos de trabalho (ensino fundamental, ensino médio e estudantes com deficiências) pautou-se em possibilitar aos acadêmicos vivenciar etapas diferentes do ensino escolar. Os materiais construídos foram e continuam sendo utilizados pelos acadêmicos que desenvolvem atividades curriculares nas escolas, como por exemplo, PIBID (Programa Institucional de Bolsas de Iniciação à Docência) e Estágios Curriculares Supervisionados (obrigatório e não obrigatório). Todos podem acessar os materiais e utiliza-los em suas regências e projetos nas escolas.

Além disso, houve uma exposição dos materiais didáticos produzidos pela disciplina na universidade, abarcando todos os produtos desenvolvidos nos três ciclos, como mostra a imagem. 
Figura 6. Painel de fotos da I Exposição de Materiais Didáticos para o ensino da Geografia.

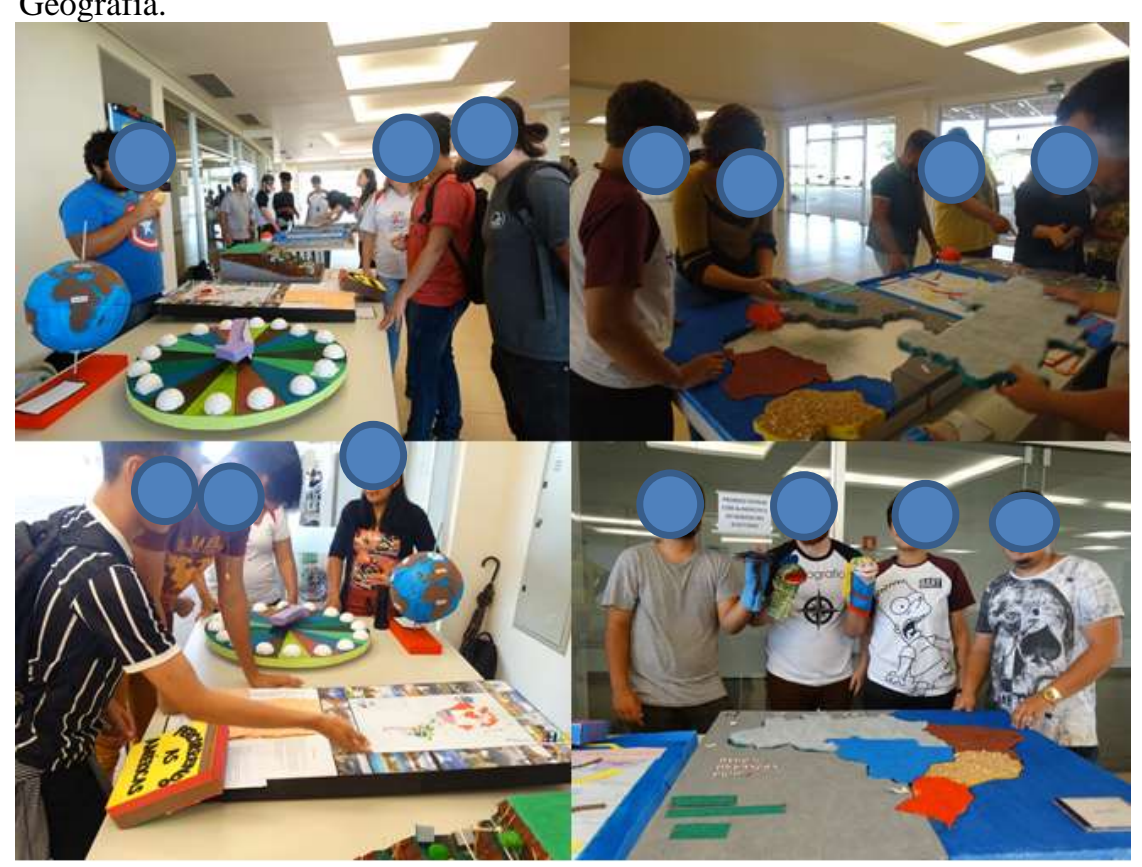

Fonte: Autores, 2018.

Através desse conjunto de atividades, observou-se o desempenho dos acadêmicos tanto no manuseio e na confecção de materiais didáticos, quanto em melhorias na desenvoltura enquanto futuro profissional da educação, devido especialmente à estratégia de simulação de aula, que permite ao acadêmico produzir o plano de aula, relacionar o conteúdo do livro didático com o tema e, trazer essas reflexões para sua aula, utilizando nesse caso, materiais didáticos.

O processo de ensino-aprendizagem na formação de docentes torna-se um ponto crucial para superação dos desafios impostos ao ensino brasileiro. Formando profissionais com qualidade e competência, permitiremos que as gerações nos bancos escolares tenham também uma formação reflexiva e integradora. 


\section{CONSIDERAÇÕES PRELIMINARES}

É um tanto complicado num tema como este propor alguma conclusão, então o que deixamos aqui é uma descrição daquilo que foi possível apreender de todo o processo apresentado.

Notadamente, os acadêmicos se envolveram em todas as etapas propostas na disciplina, trazendo até mesmo os mais dispersos e pouco participativos para o convívio do grupo. As transformações foram percebidas através da troca de experiências durante o processo, o senso colaborativo e amigável foi perceptível.

No que diz respeito às práticas de ensino, muitos relataram utilizar os materiais produzidos para reger suas aulas no estágio e nos projetos relacionados ao PIBID, nas escolas em que estão inseridos. A flexibilidade de alguns materiais permite seu uso em diferentes abordagens, para ensinar geografia, com isso, há diversas opções a serem trabalhadas, como por exemplo, os fantoches, que podem abordar outras questões em séries diferentes. Assim como o Mapa do Continente Americano, que pode servir para contextualizar vários conteúdos presentes no livro didático.

Percebe-se então, que a elaboração de tais atividades é fundamental para possibilitar aos acadêmicos, futuros profissionais, uma melhor preparação para o convívio em sala aula, possibilitando o afloramento da criatividade em construir aulas mais dinâmicas e atraentes para os estudantes. A transformação é cíclica. Os resultados são extraordinários.

\section{REFERÊNCIAS}

BRASIL, Lei nº 13.146, de 6 de julho de 2015. Institui a Lei Brasileira de Inclusão da Pessoa com Deficiência (Estatuto da Pessoa com Deficiência). Diário Oficial da União: seção, Brasília, DF, p.1-72, 7 de jul. 2015.

CALlAI, H. C. Aprendendo a ler o mundo: a geografia nos anos inicias do ensino fundamental. N. 66, Campinas: Caderno Cedes, 2005, p. 227-247.

CARLOS, A. F. A. (Org.). A geografia na sala de aula. 9. ed., $4^{\text {a }}$ reimpressão. São Paulo: Contexto, 2018. 
COPATTI, C. Livro didático de geografia: da produção ao uso em sala de aula. Élisée, Rev. Geo. UEG - Porangatu, v.6, n.2, 2017, p.74-93.

COSTA, M. S.; DAMASCENO, M. F. B.; MUNIZ, A. O uso da música e das imagens como fonte de aprendizado no ensino de Geografia. Revista de Ensino de Geografia, Uberlândia-MG, v. 9, n. 16, 2018, p.92-105.

FIORI, V. Reflexões sobre procedimentos e práticas de ensino em geografia. Práticas de ensino em Geografia nos anos finais do Ensino Fundamental. Cruzeiro do Sul Virtual, 2019.

MOREIRA JÚNIOR, O. As cidades pequenas como componente curricular para a geografia escolar. Formação, v. 02, n.23, 2016, p.20-37. 